\title{
Translation and psychometric validation of the Persian version of the Questionnaire on Smoking Urges for assessment of craving to smoke among university students
}

\author{
Maryam Kazemitabar ${ }^{\text {Corresp., 1, } 2 \text {, Danilo Garcia }}{ }^{\text {Corresp. 3, 4, 5, 6, } 7}$ \\ ${ }^{1}$ Department of Psychology, University of Tehran, Tehran, Iran \\ 2 Promotion of Health and Innovation (PHI) Lab, International Network for Well-Being, Tehran, Iran \\ 3 Department of Behavioral Sciences and Learning, Linköping University, Linköping, Sweden \\ ${ }^{4}$ Centre for Law and Mental Health (CELAM), University of Gothenburg, Gothenburg, Sweden \\ 5 Promotion of Health and Innovation (PHI) Lab, International Network for Well-Being, Linköping, Sweden \\ 6 Department of Psychology, University of Gothenburg, Gothenburg, Sweden \\ 7 Department of Psychology, Lund University, Lund, Sweden
}

Corresponding Authors: Maryam Kazemitabar, Danilo Garcia

Email address: maryam.kazemi64@ut.ac.ir, Danilo.garcia@icloud.com

\begin{abstract}
Background.Even though tobacco is one of the most preventable causes of death worldwide, it endangers more than 8 million people yearly. In this context, meta-analyses suggest that a significant part of the general Iranian population over 15 years of age smoke and that there is a need for good screening tools for smoking cravings and urges in Iran. The present study reported the translation and investigated the psychometric properties (i.e., factor structure, validity, and reliability) of the Persian version of the Questionnaire on Smoking Urges (QSU) with 12 items in the Iranian context.
\end{abstract}

Method.The translation process and content validity of the items were examined entirely in an expert panel using the Content Validity Index. The total sample of participants in which the translated version was tested consisted of 392 (172 female, 220 male, $M_{\text {age }}=22.31$ years, SD $=2.90$ ) university students who answered the QSU 12-item at the start of their participation in smoking cessation interventions. The QSU 12-item was firstly translated, then piloted using a subsample of 150 university students and finally validity and reliability of the instrument were investigated using a subsample of 242 participants. We tested the proposed models in the literature, that is, a 1-factor solution and a 2-factor solution with six items on each factor (Factor 1: desire/intention to smoke; Factor 2: relief of negative affect or withdrawal symptoms and anticipation of positive outcome). At last, we tested differences across differences in QSUscores across different subgroups of individuals based on their demographics.

Results. The results suggested that, in contrast to past studies, a modified 2-factor model, using 5 items for Factor 1 and 7 items for Factor 2, was the best fitting model $(C F I=.95, R M S E A=.09, C l=90 \%)$. Additionally, the QSU 12-item Persian version showed good convergent and divergent validity, internal consistency (Factor $1=.94$, Factor $2=.97$ ), ICC (average measure ICC $=.95, \mathrm{Cl}=95 \%, \mathrm{~F}_{(391,4301)}=$ $20.54, p<.001)$, concurrent validity $(r=.71, p<.01)$, and discriminant validity $(r=-.04, p>.05)$. Finally, subgroups based on gender, marital status, (un)employment, and educational level did not differed in their responses to the QSU 12-item. 
slight modification, it can be considered as a reliable and valid method to estimate smoking urges in the Iranian population. Moreover, the QSU 12-item seems appropriate to measure urge for smoking among groups of individuals with different sociodemographic backgrounds. Importantly, the QSU 12-item differentiates individuals' desire and intention to smoke from their anticipated relief of negative affect or withdrawal symptoms, which can be important for personalizing interventions targeting individuals who want to quit smoking. 
1 Translation and psychometric validation of the Persian version of the Questionnaire on

3

4 Maryam Kazemitabar 1,2*, Ph.D.

5 Danilo Garcia ${ }^{3,4,5,6,7 *}$, Ph.D.

6

7 1. Department of Psychology, University of Tehran, Tehran, Iran

8 2. Promotion of Health and Innovation (PHI) Lab, International Network for Well-Being, Iran

9 3. Department of Behavioral Sciences and Learning, Linköping University, Linköping, Sweden

10 4. Centre for Law and Mental Health (CELAM), University of Gothenburg, Gothenburg, Sweden
5. Promotion of Health and Innovation (PHI) Lab, International Network for Well-Being, Sweden

6. Department of Psychology, University of Gothenburg, Gothenburg, Sweden

7. Department of Psychology, Lund University, Lund, Sweden

*Proofs and Correspondences:

E-mail: maryam.kazemi64@ut.ac.ir

E-mail: danilo.garcia@icloud.com

Contributorship

Maryam Kazemitabar designed the study, conducted the data collection, analyzed the data, and together with Danilo Garcia wrote the paper, revised the paper, and interpreted the data. 


\section{Abstract}

Background. Even though tobacco is one of the most preventable causes of death worldwide, it endangers more than 8 million people yearly. In this context, meta-analyses suggest that a significant part of the general Iranian population over 15 years of age smoke and that there is a need for good screening tools for smoking cravings and urges in Iran. The present study reported the translation and investigated the psychometric properties (i.e., factor structure, validity, and reliability) of the Persian version of the Questionnaire on Smoking Urges (QSU) with 12 items in the Iranian context.

Method. The translation process and content validity of the items were examined entirely in an expert panel using the Content Validity Index. The total sample of participants in which the translated version was tested consisted of 392 (172 female, 220 male, $\mathrm{M}_{\mathrm{age}}=22.31$ years, $\mathrm{SD}=$ 2.90) university students who answered the QSU 12-item at the start of their participation in smoking cessation interventions. The QSU 12-item was firstly translated, then piloted using a subsample of 150 university students and finally validity and reliability of the instrument were investigated using a subsample of 242 participants. We tested the proposed models in the literature, that is, a 1-factor solution and a 2-factor solution with six items on each factor (Factor 1: desire/intention to smoke; Factor 2: relief of negative affect or withdrawal symptoms and anticipation of positive outcome). At last, we tested differences across differences in QSU-scores across different subgroups of individuals based on their demographics.

Results. The results suggested that, in contrast to past studies, a modified 2-factor model, using 5 items for Factor 1 and 7 items for Factor 2, was the best fitting model (CFI = .95, RMSEA = $.09, \mathrm{CI}=90 \%)$. Additionally, the QSU 12-item Persian version showed good convergent and divergent validity, internal consistency (Factor $1=.94$, Factor $2=.97$ ), ICC (average measure $\left.\mathrm{ICC}=.95, \mathrm{CI}=95 \%, \mathrm{~F}_{(391,4301)}=20.54, p<.001\right)$, concurrent validity $(r=.71, p<.01)$, and discriminant validity $(r=-.04, p>.05)$. Finally, subgroups based on gender, marital status, (un)employment, and educational level did not differed in their responses to the QSU 12-item. Conclusion. The Persian version of the QSU 12-item has satisfactory psychometric properties and, with a slight modification, it can be considered as a reliable and valid method to estimate smoking urges in the Iranian population. Moreover, the QSU 12-item seems appropriate to measure urge for smoking among groups of individuals with different sociodemographic backgrounds. Importantly, the QSU 12-item differentiates individuals' desire and intention to smoke from their anticipated relief of negative affect or withdrawal symptoms, which can be important for personalizing interventions targeting individuals who want to quit smoking.

Keywords. Smoking Urges, Smoking Cessation, Psychometric Properties, Smoking Craving, QSU, Questionnaire on Smoking Urges, Validity and Reliability 
76

77

78

Smoking is one of the biggest global health challenges and a high-risk factor for premature death. Even though tobacco is one of the most preventable causes of death worldwide, it is the cause of death of more than 8 million people/year (World Health Organization, 2008). Above 7 million of those deaths are a direct result from tobacco use and around 1.2 million deaths are non-smokers exposed to second-hand smoke (World Health Organization, 2020). Smoking is also associated with many health issues such as sleep problems (Bellatorre, 2017), hypertension, myocardial infraction and respiratory diseases (Gao, Shi \& Wang, 2017), type 2 diabetes (Yuan \& Larsson, 2019), schizophrenia spectrum disorders (Scott et al., 2018), stroke (Pan et al., 2019), cardiovascular injury (Al Rifai et al., 2017), lower subjective well-being (Churchill \& Farrell, 2017), poor mental health (Bang et al., 2017), and etcetera.

One of the most important motives for smoking is craving and urging for it. Craving for smoking is defined as persistent urges, thoughts, or desire to smoke a cigarette (Potvin et al., 2015). It is considered a common symptom of addiction and identified as one of the characteristics of psychoactive substance dependence (American Psychiatric Association, 2013) and is also one of the important causes of maintenance of addiction (Serre et al., 2018) and associated with smoking relapse in individuals who seek smoking cessation interventions (Motschman, Germeroth \& Tiffany, 2018; Chatterjee et al., 2016; Killen \& Fortmann, 1997). Hereupon, measuring craving is important prior to starting any smoking cessation intervention (Waters et al., 2013; Shiffman, West \& Gilbert, 2004) as decrease in craving for smoking would be effective in successful treatments (Enkema \& Bowen, 2017).

There are several similar questionnaires measuring the desire and craving for smoking such as Smoking initiation for Women Questionnaire (Shahbazi et al., 2019), Nicotine Dependence 
98 Syndrome Scale (Shiffman, Waters \& Hickcox, 2004), Willingness to Quit (Onchonga et al.,

99 2020), and Tobacco Craving Questionnaire (Heishman, Singleton \& Moolchan, 2003).

100 Nevertheless, one of the most commonly used measures is the Questionnaire on Smoking Urges

101 (QSU), which was initially developed by Tiffany and Drobes (1991). The QSU comprises 32

102 items measuring two factors and four categories. Factor 1 indicates a) the desire to smoke, and b)

103 anticipation of pleasure from smoking; Factor 2 indicates c) anticipation of relief from negative

104 affect and withdrawal symptoms and d) intention to smoke. In the original study, the internal

105 consistency for Factor 1 was estimated to .95 and for Factor 2 to .93 (Tiffany \& Drobes, 1991),

106 thus, acknowledging the QSU 32-items as a highly reliable scale. Different shorter versions of

107 the QSU include a 26-item version by Tiffany and Drobes (1991), a 12-item version by

108 Kozlowski et al (1996), and a 10-item version proposed by Cox et al (2001). The QSU 12-item

109 had the highest goodness of fit when compared to both the original 32-item and the 26-item

110 versions (Toll et al., 2004; Dethier et al., 2014). Hence, the 12-item version was not only brief

111 and convenient, but also of great interest for research and clinical practice due to its good

112 psychometric properties.

113 The QSU 12-item has been adapted, studied, and validated in several languages, including

114 French (Dethier et al., 2014; Guillin et al., 2000), Spanish (Cepeda-Benito \& Reig-Ferrer, 2004),

115 Portuguese (Araujo et al., 2007), Chinese (Yu et al., 2010), Italian (Teneggi et al., 2001), and

116 German (Müller et al., 2001). However, it has not yet been validated in Persian. As the matter of

117 fact, to the best of our knowledge, there is no standard and validated instrument for measuring

118 urge for smoking exists in the Persian language. Importantly, meta-analyses implied that a

119 significant part of the general Iranian population over 15 years of age smoke (e.g., Moosazadeh

120 et al., 2013). Thus, suggesting the need for a good screening tool for smoking cravings and urges 
121 in Iran. Hence, this study aimed to report the translation and investigate the psychometric

122 properties of the Persian version of the QSU 12-item in an Iranian population. In this endeavor,

123 we analyzed both the 1-factor and 2-factor solutions of the QSU 12-item and investigated its

124 validity (i.e., convergent, divergent, discriminant, and concurrent validity) and reliability (i.e.,

125 internal consistency).

\section{Method}

\section{Ethical Statement}

128 The participants provided informed consent before replying to the questionnaires and sufficient

129 information was provided regarding the aims of the research. They were also assured of the 130 confidentiality of their information. This study received ethical approval from the Department of

131 Psychology, Faculty of Psychology and Educational Sciences, University of Tehran (document 132 reference: $2416-14)$.

\section{Participants}

134 The data was collected within a period of six months from November 2015 to May 2016, except

135 for several days in March and April during Iran's New Year holiday. The participants, a

136 convenient sample, consisted of 416 university students with the following criteria: being a

137 cigarette smoker who voluntarily sought to participate in smoking cessation interventions, being

138 a university student, and have started smoking on a daily basis for at least one year. The students

139 who smoked only occasionally were excluded from the study. The participants were students at

140 Tehran University of Art, College of Fine Arts of University of Tehran, Amirkabir University of

141 Technology (Tehran Polytechnic), and Islamic Azad University of Tehran (North Branch). 
142 A total of 24 participants were removed due to incomplete answers (i.e., about $6 \%$ attrition).

143 Hence, 392 individuals $\left(\mathrm{M}_{\mathrm{age}}=22.31\right.$ years, $\left.\mathrm{SD}=2.90\right)$ constituted the data that was analyzed in

144 the present study (i.e., a survey response rate of 94\%). Regarding gender, 172 participants

145 (43.9\%) were females and 220 (56.1\%) were males. The average age for females' first smoking

146 experience was 18.55 years and 18.81 years for males; with a total mean of 18.70 years $(\mathrm{SD}=$

147 2.62) for both genders. Regarding marriage status, 353 individuals were single and 39 were

148 married. Furthermore, 118 individuals were employed for wages and 274 were unemployed.

149 Finally, a total of 288 individuals $(73.5 \%)$ stated that they had at least one smoker member in

150 their families besides themselves and 104 individuals (26.5\%) stated that they were the only

151 smoker in their family. Concerning educational levels, 246 of the participants were bachelor's

152 students (62.8\%), 133 were master's students (33.9\%), and 13 were associate's students (3.3\%).

\section{Measures}

154 Questionnaire on Smoking Urges 12-item version (QSU 12-item).

155 The QSU 12-item (Kozlowski et al., 1996) is a self-report that measures urge and craving to 156 smoke with 12 statements that are rated using a seven-point Likert scale ranging from 1 (strongly

157 disagree) to 7 (strongly agree). Four of the 12 items ("Smoking a cigarette would not be

158 pleasant.", "Even if it were possible, I probably wouldn’t smoke now.", "I have no desire for a

159 cigarette right now", and "A cigarette would not taste good right now.") are scored reversely. In 160 the present study, the QSU 12-item was translated into Persian following the process described 161 in the Procedure section.

162 Nicotine Dependency Syndrome Scale (NDSS) 
163 The NDSS is a multidimensional scale assessing dependency to nicotine (Shiffman et al., 2004).

164 It contains 19 items that are rated using a five-point Likert scale scoring from 1 (completely

165 incorrect) to 5 (completely correct). The NDSS scale has five subscales: drive (craving and

166 withdrawal, and subjective compulsion to smoke), priority (preference for smoking over other

167 reinforces), tolerance (reduced sensitivity to the effects of smoking), continuity (regularity of

168 smoking rate), and stereotypy (invariance of smoking). All items are non-reversed.

Self-Motivation for Smoking Cessation (MSC)

170 The MSC (Joseph et al., 2005) measures self-motivation for quit smoking. It consists of 12 items

171 with a seven-point Likert scale response ranging from 1 (completely disagree) to 7 (completely

172 agree). This scale comprises two factors with six items each: autonomous regulation and

173 controlled regulation.

174 Procedure

175 Translation Process of the QSU 12-item

176 An expert panel consisting of two professors of the English language and two specialists with

177 Ph.D. degrees in psychology translated the original QSU 12-item into Persian and back-

178 translated the items. The translation was conducted for each item with precision and accuracy

179 while trying to keep the meaning of the original items. Then, the items were back-translated into

180 English in order to depict the initial translation by another translator who was not involved in the

181 first translation from English to Persian. Both Persian and English items were compared in detail.

182 Eventually, the first draft of the QSU 12-item Persian version was finalized after some minor

183 revisions and corrections such as grammatical error corrections and providing synonyms for

184 some words that could transfer the meaning of the original items literally and accurately. 
185 This version was administered in a sample of 25 examinees ( 15 males and 10 females, $\mathrm{M}_{\text {age }}=$

18623.6 years, $\mathrm{SD}=1.4)$ to investigate the comprehensiveness and clarity of the items. The

187 questionnaire was also scrutinized in terms of content validity in an expert group including 10

188 psychology professors. They scored each item regarding clarity and comprehensiveness using the

189 Content Validity Index (Waltz \& Bausell, 1981) using a four-point rating scale ( $1=$ bad, to $4=$

190 very good). All 12 items achieved good content validity scores at this stage. The Content

191 Validity Index scores for the items are provided in Appendix 1.

192 Data analysis

193 As the first step, we tested the normal distribution of the data by investigating the skewness and

194 kurtosis. Second, through exploratory factor analysis, the number of factors and items' factor

195 loadings were checked. We conducted both analyses using SPSS v24. Then, we performed a

196 confirmatory factor analysis using Mplus v8.3 (Muthén \& Muthén, 2009). For each analysis,

197 different data subsets were used; a procedure recommended when researchers conduct both

198 exploratory factor analysis and confirmatory factor analysis (Worthington \& Whittaker, 2006).

199 Using the maximum likelihood estimation method, we tested three models comprising (1) single-

200 factor solution, (2) two-factor solution, and (3) two-factor solution with six items for each

201 subscale (i.e., original model). The fit indices of the chi-square statistics (Hatcher, 2009),

202 comparative fit index (CFI; Bentler \& Wu, 1998), Tucker-Lewis index (TLI; Tucker \& Lewis,

203 1973), standardized root-mean-square residual (SRMR; Jöreskog \& Sörbom, 1981), and root-

204 mean-square error of approximation (RMSEA; NE \& Cudeck, 1993) were estimated for all three

205 models. Additionally, the multicollinearity between factors was estimated. Sample size for

206 exploratory factor analysis was calculated at least 10 times the items (Nunnally, 1976) and for 
207 confirmatory factor analysis it was calculated using GPower v3.1 (Faul et al., 2007). Convergent

208 and divergent validity were also calculated using Fornell and Larcker's (1981) criterion.

209 Internal consistency of the subscales and the total construct were measured by Cronbach's alpha

210 as the measure for reliability (Revelle \& Zinbarg, 2009) and intraclass correlation coefficient.

211 Concurrent validity was assessed by comparing the QSU 12-item to the NDSS and estimating the

212 Pearson correlation coefficient between them; the mean scores and standard deviations for both

213 scales were also calculated and reported. For the evaluation of QSU 12-item' discriminant

214 validity, we estimated the Pearson correlation coefficients between QSU 12-item and the MSC.

215 The differences in responses to the QSU 12-item in subgroups of gender, marriage status,

216 employment status, and educational level were studied as the final analysis.

\section{Results}

218

219

220

221

222

223

224

225

226

227

228

\section{Normality Test of the Data}

The skewness and kurtosis normality assumptions were tested before conducting the factor analyses. The skewness ranged between -1.07 and -.25 and the kurtosis ranged between -.63 and .71. Hence the distribution of the data was assumed as normal (Hair et al., 2017).

\section{Maximum Likelihood Exploratory Factor Analysis}

The subsample size of 150 participants was estimated as sufficient $(\mathrm{KMO}=.93)$ for conducting the exploratory factor analysis. In addition, the Bartlett's test of sphericity showed that the items were sufficiently correlated for conducting a factor analysis (chi-square $=2347.32, d f=66, p<$ $.01)$. The analysis showed that there were two factors with eigenvalues higher than one and that these two factors accounted for $86.47 \%$ of the total variance. The first factor determined $61.31 \%$ and the second component $25.15 \%$ of the total variance (Table 1 ).

Peer] reviewing PDF | (2021:03:59268:3:0:CHECK 1 Nov 2021) 
229 The items $1,2,4,7,9,10$, and 12 were located within one factor and the items 3, 5, 6, 8, and 11

230 within the other factor $\left(\chi^{2}=99.90, \mathrm{df}=43, p<.01\right)$. The $\chi^{2} / \mathrm{df}=2.32$ indicated a good model fit.

231 All items had factor loadings higher than .85 after rotation converged in three iterations. The

232 extraction method was maximum likelihood and the rotation method was Oblimin with Kaiser

233 Normalization, which is an oblique rotation. Oblique rotation is used when it is assumed that the

234 factors are correlated (Kieffer, 1998); which according to the literature, is the case for the QSU

235 12-item' factors. Next, a confirmatory factor analysis was performed in order to acquire adequate

236 support for the results from the exploratory factor analysis.

\section{Confirmatory Factor Analysis}

238 The confirmatory factor analysis was performed for the single-factor solution, for the proposed modified two-factor solution (based on the exploratory factor analysis), and for the original two-

240 factor solution using maximum likelihood estimation method in Mplus v8.3 on a sample of 242

241 participants. Thus, as suggested in the literature (Worthington \& Whittaker, 2006), the

242 subsamples used in the exploratory factor analysis and the confirmatory factor analysis were not

243 the same. The comparison between these three models showed that the modified two-factor

244 model had a better fit. In this model, unlike the original model proposed by Tiffany and Drobes

245 (1991), item number 9 (I have an urge for a cigarette) fitted better on Factor 2 instead of Factor 1

246 by showing a higher factor loading for this item on Factor $2(.91)$ rather than Factor $1(.21)$. The

247 modified two-factor model exhibited better fit indices compared to the single-factor model and

248 the original two-factor model (see Table 2).

249 All three models had significant chi-square statistics $(p<.01)$, but the modified two-factor model

250 had better chi-square goodness of fit value. The RMSEA for the single-factor model (.25) and

251 the original two-factor (.19) were, however, unacceptable. In the modified two-factor model, the 
252 RMSEA $(\mathrm{CI}=90 \%)$ was marginal (.09). The CFI values for single-factor model (.76), modified

253 two-factor model (.97), and original two-factor model (.86) were calculated. The general

254 acceptable CFI value should be above .95 which is achieved by the modified two-factor model in

255 our CFA analysis. The SRMR value in the single-factor (.14) and the original two-factor (.12)

256 models were high, which suggested a poor fit for the data, while in the modified two-factor

257 model it was very low (.03), thus, indicating a low residual error in this specific model.

258 According to $\mathrm{Hu}$ and Bentler (1999), a CFI and TLI $\geq .95$, a SRMR $\leq .08$, and a RMSEA $\leq .06$

259 are needed to conclude that the hypothesized model has a relatively good fit to the observed data.

260 Therefore, we argue that the modified two-factor model had the best fit rather than the single-

261 factor and the original two-factor models. The multicollinearity between Factor 1 and Factor 2 in

262 the modified two-factor model was estimated as low $($ Tolerance $=1.00, \mathrm{VIF}=1.00)$. Figure 1

263 represents the modified two-factor model of the QSU 12-item ${ }^{1}$. Factor loadings, standard errors,

264 t-values, and p-values of the items are presented in Appendix 2. The next analyses were

265 conducted using the modified two-factor solution.

\section{Convergent and Divergent Validity}

267 Table 3 shows composite reliability (CR), average variance extracted (AVE), and AVE squared

268 for Factor 1 and 2. According to Fornell and Larcker (1981), convergent validity is approved if

$269 \mathrm{AVE}>.5$ and $\mathrm{AVE}<\mathrm{CR}$ and divergent validity is confirmed if the AVE square root of each

\footnotetext{
${ }^{1}$ The items 3 (Smoking a cigarette would not be pleasant.), 5 (Even if it were possible, I probably wouldn't smoke now.), 6 (I have no desire for a cigarette right now.), 8 (A cigarette would not taste good right now.), and 11 (I am going to smoke as soon as possible.) were placed in Factor 1. The items 1 (Nothing would be better than smoking a cigarette right now.), 2 (Smoking would make me less depressed.), 4 (All I want right now is a cigarette.), 7 (Smoking now would make things seem just perfect.), 9 (I have an urge for a cigarette.), 10 (I could control things better right now if I could smoke.), and 12 (I would do almost anything for a cigarette now.) were located in Factor 2. Persian version of the QSU-12 item (in Farsi) is presented in Appendix 3.
} 
270 factors is greater than the correlations between factors $(r=.51)$. The obtained results suggested

271 that the QSU 12-item' factors had sufficient convergent and divergent validity.

272 Reliability

273 Internal consistency, as a measure of reliability, was assessed using Cronbach's alpha (Bonett \&

274 Wright, 2015) for each factor independently as recommended elsewhere (e.g., Kazemitabar et al.,

275 2020). The Cronbach's alphas for Factor $1(\alpha=.94)$ and Factor $2(\alpha=.97)$, and for the total

276 construct $(\alpha=.95)$ suggested high internal consistency between the items in each factor. The

277 intraclass correlation coefficient was also measured using a two-way random effect model

278 (average measure $\mathrm{ICC}=.95, \mathrm{CI}=95 \%, \mathrm{~F}_{(391,4301)}=20.54, p<.001$ ) and indicated that the QSU

279 12-item had high reliability. Table 4 shows that the items within each factor had high

280 correlations $(r \geq .71)$ with each other and lower correlations $(r \leq .53)$ with items from the other

281 factor. Moreover, the correlation between the two factors $(r=.51, p<.001)$ showed there was a

282 moderate positive relationship between them.

283 Concurrent validity: QSU 12-item and NDSS

284 The NDSS measurement properties has been investigated in several studies. For example, 285 Costello et al (2007) studied the factor analysis of this scale in an American college sample.

286 Their results showed a CFI equal to .95 and an RMSEA equal to .06. Sterling and colleagues

287 (2009) also measured the psychometric properties of the NDSS among teens and the results

288 indicated alpha ranging from .64 to $.92, \mathrm{CFI}=.94$, and RMSEA $=.09$; hence, suggesting a good

289 fit to their data. In other words, it had high validity and reliability to measure the nicotine

290 dependency. 
291 In the present study, the Pearson correlation between the QSU 12-item and the NDSS was

292 relatively high and positive $(r=.71, p<.01)$, that is, the higher the smoking urges and cravings

293 are, the higher the nicotine dependency is. That is, indicating a fair concurrent validity between

294 these two scales. The mean score for the NDSS was $65.00(\mathrm{SD}=9.23)$ and for the QSU 12-item

295 the mean score was $64.99(\mathrm{SD}=12.95)$.

296 Discriminant validity: QSU 12-item and MSC

297 Previous studies showed that the MSC is valid and reliable. For instance, Çelik (2014) measured 298 the factorial structure of the MSC in a Turkish sample, the results showed a good fit to the data $299(\mathrm{CFI}=.93, \mathrm{GFI}=.92, \mathrm{RMSEA}=.08, \mathrm{SRMR}=.06)$ with good internal consistency $(.81$ and .76$)$. 300 In the present study, the correlation between the MSC and NDSS was nonsignificant $(r=-.08, p$ $301>.05)$. Likewise, the correlation between the QSU 12-item and the MSC was also nonsignificant $302(r=-.04, p>.05)$. In other words, there was no relationship between them and despite being 303 slightly negative, which was expected, the correlation between the MSC and the QSU 12-item 304 was extremely low.

Differences between Groups: Gender, Marital Status, Education, and Employment

306

307

308

309

310

311

The normality of residual assumption for conducting parametric tests showed non-normality of the residuals for the different demographic groups. Therefore, non-parametric analyses, MannWhitney and Kruskal-Wallis, were used to investigate differences in craving and urge for smoking between individuals with different gender, marriage status, educational level, and employment status. No significant differences were detected within subgroups for the total QSU 12-item score $(p>.05)$ or for Factor 1 (i.e., desire/intention to smoke) and Factor 2 (i.e., relief of 
312 negative affect or withdrawal symptoms and anticipation of a positive outcome) $(p>.05)$ (see

313 Table 5).

\section{Discussion}

315 The present study reported the translation and examined the psychometric properties of the

316 Persian version of the QSU 12-item in an Iranian population of university students. This was, as

317 far as we know, the first translation and validation study of the QSU 12-item in the Persian

318 language. For this purpose, the translation process and content validity were examined entirely

319 by a panel of expert panel, who judged the translation as satisfactory. Then, the exploratory

320 factor analysis found two factors with five items that loaded on one of the factors and the other

321 seven items on the second factor (loadings ranging from .85 to .95) - that is, a modified two-

322 factor solution. On this basis and past findings from the literature, we tested three models (i.e.,

323 single-factor, original two-factor, and the proposed modified two-factor solutions) through

324 confirmatory factor analysis. The goodness of fit indices obtained from each model suggested

325 that the modified two-factor structure had the best fit. Moreover, Cronbach's alpha coefficients

326 showed high reliability for the total score and for the subfactors in this modified two-factor

327 solution. Our findings are partially consistent with past studies that have confirmed a two-factor

328 solution for the QSU 12-item (e.g., Tiffany \& Drobes, 1991; Toll et al., 2004; Dethier et al.,

329 2014; Cepeda-Benito et al., 2004).

330 Nevertheless, the exploratory and confirmatory factor analyses indicated that Factor 1

331 (desire/intention to smoke) consisted of five items and that Factor 2 (relief of negative affect or

332 withdrawal symptoms and anticipation of positive outcome) consisted of seven items. This was

333 slightly different from past studies suggesting six items for each factor (e.g., Kozlowski et al.,

334 1996; Toll et al., 2004). More specifically, item 9 "I have an urge for a cigarette" in the original 
335

336

337

338

339

340

341

342

343

344

345

346 347 item.

348

version belonged to Factor 1 (desire/intention to smoke), but in the modified two-factor solution in the present study, item 9 had significantly higher factor loading on Factor 2 (relief of negative affect/withdrawal symptoms). This finding was, however, in line with the validation of the QSU 12-item French version (Dethier et al., 2014), in which this very same item also loaded on the Factor 2 (relief of negative affect/withdrawal symptoms). According to these researchers, this was due to a translation error by the original French translators (i.e., Guillin et al., 199) when they developed the French QSU— the word "urge" was translated to suggest an "urgent need" rather than a "strong desire" (Dethier et al., 2014). Thus, making the item semantic content more closely related the concept measured in Factor 2, the anticipation of relief of negative affect and withdrawal symptoms. Although, this might be the case for the Persian version developed here, our translation (see Appendix 3) is more attuned with "having a strong desire", thus, we attribute the modification of the two-factor solution to the actual psychometric properties of the QSU 12-

In this context, the modified two-factor model showed high goodness of fit $(\mathrm{CFI}=.95, \mathrm{TLI}=$ .94) while the error value was marginal (RMSEA $=.09, \mathrm{CI}=90 \%)$ (cf. Hair et al., 1998). Browne and Cudek (1992) suggested that values of .08 or lower for RMSEA demonstrate a reasonable fit. Some other researchers, however, have more strict criteria for RMSEA cutoff points and propose the value of .05 or less as acceptable (Kyle, 1999); while there is also a moderate cutoff of .06 provided by $\mathrm{Hu}$ and Bentler (1999). Some other studies have shown that increasing the number of variables resulted in a decrease in the RMSEA value (Bentler \& Wu, 1998; Breivik \& Olsson, 2001). Importantly, Kenny and McCoach (2003) described that the decline in RMSEA was a result of decreasing the ratio of chi-square to its degree of freedom. Thus, the small number of observed variables (i.e., items) in the QSU 12-item might explain the 
358 relatively high value for RMSEA in the present study for the modified two-factor solution that

359 we recommend. Depending on the cut off used for RMSEA, however, this might be a limitation

360 with our proposed model.

361 Moreover, there are arguments concerning the use of different approaches to exploratory and

362 confirmatory factor analyses in both scale construction studies and validation studies. For

363 example, while some recommend exploratory factor analysis as an intermediate stage before

364 conducting a confirmatory factor analysis (Brown, 2015), other researchers suggested employing

365 either one or the other, but definitely not both type of analysis (Kline, 2015). However, using

366 exploratory factor analysis followed by confirmatory factor analysis is one of the most common

367 methods applied for tool development and validation studies (Worthington \& Whittaker, 2006).

368 Many validation studies recommend to, as performed in the current study, first conduct an

369 exploratory factor analysis to measure the underlying factor structure, followed by a

370 confirmatory factor analysis using different samples (Costello \& Osborne, 2005; Henson \&

371 Roberts, 2006; Worthington \& Whittaker, 2006).

372 Furthermore, the maximum likelihood exploratory factor analysis, used here, and principal factor

373 analysis are two approaches that have been regularly used in exploratory factor analysis.

374 Although, there is another recent method named "regularized exploratory factor analysis"

375 suitable for small samples, in which only one parameter is supposed to be estimated (Jung \&

376 Takane, 2008). Principal component analysis is wrongly considered as factor analysis as it does

377 not distinctly assess measurement error. In contrast to principal factor analysis, the maximum

378 likelihood exploratory factor analysis we used here explicitly considers the measurement errors

379 of the observed variables. Also in this line, principal factor analysis does not differentiate the

380 variances and explain all variance in the model while exploratory factor analysis explains 
381 common variance. Finally, exploratory factor analysis is not based on a testable model, hence, it

382 is not able to accept or reject a model fit (Norris \& Lecavalier, 2010). For all these reasons, we

383 found maximum likelihood exploratory factor analysis as the best suitable approach in our study.

384 We investigated the QSU 12-item' construct validity using concurrent and discriminant validity.

385 We found that the direction and magnitude of the correlation between comparable instruments

386 showed that the Persian QSU 12-item' modified two-factor solution was a valid scale to measure

387 urge for smoking among university students — craving and urges for smoking as measured by the

388 Persian QSU 12-item was associated with nicotine dependence and as nicotine dependence, it

389 was weakly and negatively associated with intention to quit smoking. Last but not the least, how

390 a scale performs among subgroups of a sample is important as it reveals whether it measures the

391 construct among subgroups sufficiently. In this regard, subgroups of females and males, married

392 or single, employed or unemployed, and individuals with different educational levels did not

393 differed in their responses to the QSU 12-item. Thus, the questionnaire seems appropriate to

394 measure urge for smoking among these subgroups.

\section{Limitations, future directions, and implications}

396 Future validation studies of the Persian QSU 12-item should measure test-retest reliability, which

397 is suggested to be a stronger measure to estimate reliability than just, as we did here, reporting

398 Cronbach's alpha (Taber, 2018). Measurement of beta (Revelle \& Zinbarg, 2009) or omega

399 (Nima, 2020) as measures of reliability are also recommended. Since the population in this study

400 was limited to university students, we suggest researchers to include more diverse populations in

401 future studies. In addition, measuring cross-cultural validation and measurement invariance for

402 language or ethnicity would be helpful. Perhaps this might help to explain the issues with item 9,

403 which loaded in Factor 2 instead of Factor 1 as in the original English validation. 
404 Nevertheless, despite these limitations, the QSU 12-item Persian version developed in this study

405 can be utilized in various sectors, such as, health-related clinics, organizations encouraging

406 employer to quit smoking, schools, and research institutions with the aim of screening and

407 diagnosing for smoking craving and urges of individuals seeking treatment. This questionnaire

408 can also be employed in intervention and prevention studies using experimental or quasi-

409 experimental designs.

\section{Conclusion}

411 Our findings suggested that the Persian version of the QSU 12-item has satisfactory

412 psychometric properties and with a slight modification, it can be considered as a reliable and

413 valid method to estimate smoking urges in the Iranian population. Moreover, the QSU 12-item

414 was useful to predict nicotine dependence and seems appropriate to measure urge for smoking

415 among groups of individuals with different sociodemographic backgrounds. Importantly, the

416 QSU 12-item differentiates individuals' desire and intention to smoke from their anticipated

417 relief of negative affect or withdrawal symptoms, which can be important for personalizing

418 interventions targeting individuals who want to quit smoking. We argue that this is important,

419 especially in light of the current and future challenges of the $21^{\text {st }}$ century. For instance, during

420 the current pandemic, individuals diagnosed with substance use disorders have had a higher risk

421 of COVID-19 and several serious diseases (Wang et al., 2021). In such conditions, is not only

422 our health at stake, but it is difficult to make healthy self-directed choices necessary to be

423 resilient during these challenges (Wong \& Cloninger, 2010). Thus, we need to identify methods

424 to measure and understand what makes people crave for unhealthy ways of handling stress,

425 anxiety, fear, depression, or plain boredom (Cloninger. 2004, 2013).

\section{Ethical statements}


427 The authors confirm that the following statements are fulfilled in this research:

428 - This study reflects the authors' own research and analysis.

429 - All authors collaborated actively in substantial work leading to this accomplished study.

430 - The authors will take public responsibility for the whole content of the study.

431 - This study approves the worthwhile contributions of the authors.

432 - This study is a result of the authors' data, statistical analyses, research, and is an original

$433 \quad$ work.

434 - All utilized sources are disclosed properly and correctly through citations.

435 Conflicts of interest

436 The authors declare that they have no conflicts of interest.

437 References

438 Al Nima A, Cloninger KM, Lucchese F, Sikström S, Garcia D. 2020. Validation of a general 439 subjective well-being factor using Classical Test Theory. PeerJ 8:e9193.

440 https://doi.org/10.7717/peerj.9193

441 Al Rifai M, DeFilippis AP, McEvoy JW, Hall ME, Acien AN, Jones MR, Keith R, Magid

442 HS, Rodriguez CJ, Barr GR, Benjamin EJ. 2017. The relationship between smoking intensity 443 and subclinical cardiovascular injury: The Multi-Ethnic Study of Atherosclerosis (MESA).

444 Atherosclerosis 258:119-30. https://doi.org/10.1016/j.atherosclerosis.2017.01.021

445 American Psychiatric Association. 2013. Diagnostic and Statistical Manual of Mental

446 Disorders. 5th ed. Washington, DC: American Psychiatric Publishing.

447 Araujo RB, Oliveira MD, Moraes JF, Pedroso RS, Port F, Castro MD. 2007. Validation of 448 the Brazilian version of Questionnaire of Smoking Urges-Brief. Archives of Clinical Psychiatry 449 (São Paulo) 34(4):166-75. http://dx.doi.org/10.1590/S0101-60832007000400002

450 Bang I, Jeong YJ, Park YY, Moon NY, Lee J, Jeon TH. 2017. Secondhand smoking is 451 associated with poor mental health in Korean adolescents. The Tohoku Journal of Experimental 452 Medicine 242(4):317-26. https://doi.org/10.1620/tjem.242.317

453 Bellatorre A, Choi K, Lewin D, Haynie D, Simons-Morton B. 2017. Relationships between 454 smoking and sleep problems in black and white adolescents. Sleep 40(1).

455 https://doi.org/10.1093/sleep/zsw031

456 Bentler PM, Wu E. 1998. EQS for windows (version 5.7). Encino, CA: Multivariate Software. 
457 Bentler PM. 1990. Comparative fit indexes in structural models. Psychological bulletin 458 107(2):238. https://doi.org/10.1037/0033-2909.107.2.238

459 Bonett DG, Wright TA. 2015. Cronbach's alpha reliability: Interval estimation, hypothesis 460 testing, and sample size planning. Journal of Organizational Behavior 36(1):3-15.

461 https://doi.org/10.1002/job.1960

462 Breivik E, Olsson UH. 2001. Adding variables to improve fit: The effect of model size on fit 463 assessment in LISREL. Structural equation modeling: Present and future 169-94.

464 Brown TA. 2015. Confirmatory factor analysis for applied research. Guilford publications.

465

466

467

468

469

470

471

472

473

474

475

476

477

478

479

480

481

482

483

484

485

486

487

488

489

490

491

492

493

494

Browne MW, Cudeck R. 1992. Alternative ways of assessing model fit. Sociological methods \& research 21(2):230-58. https://doi.org/10.1177\%2F0049124192021002005

Çelik E. 2014. Factorial structure and psychometric properties of self-motivation for smoking cessation scale in a sample of Turkish adolescents. European Journal of Research on Education 2(1):47-54.

Cepeda-Benito A, Reig-Ferrer A. 2004. Development of a brief questionnaire of smoking urges--Spanish. Psychological assessment 16(4):402. https://doi.org/10.1037/1040$\underline{3590.16 .4 .402}$

Chatterjee S, Hovsepian K, Sarker H, Saleheen N, al'Absi M, Atluri G, Ertin E, Lam C, Lemieux A, Nakajima M, Spring B. 2016. mCrave: continuous estimation of craving during smoking cessation. InProceedings of the 2016 ACM International Joint Conference on Pervasive and Ubiquitous Computing 863-874. https://doi.org/10.1145/2971648.2971672

Churchill SA, Farrell L. 2017. Investigating the relationship between smoking and subjective welfare. Journal of Behavioral and Experimental Economics 71:1-2.

https://doi.org/10.1016/j.socec.2017.08.003

Cloninger, C. R. 2004. Feeling good: the science of well-being. Oxford University Press.

Cloninger, C. R. 2013. What Makes People Healthy, Happy, and Fulfilled in the Face of Current World Challenges? Mens Sana Monographs, 11, 16-24. doi: 10.4103/09731229.109288.

Costello AB, Osborne J. 2005. Best practices in exploratory factor analysis: Four recommendations for getting the most from your analysis. Practical assessment, research, and evaluation 10(1):7. https://doi.org/10.7275/jyj1-4868

Costello D, Dierker L, Sledjeski E, Flaherty B, Flay B, Shiffman S. 2007. Confirmatory factor analysis of the Nicotine Dependence Syndrome Scale in an American college sample of light smokers. Nicotine \& Tobacco Research 9(8):811-819.

https://doi.org/10.1080/14622200701484979

Cox LS, Tiffany ST, Christen AG. 2001. Evaluation of the brief questionnaire of smoking urges (QSU-brief) in laboratory and clinical settings. Nicotine \& tobacco research 3(1):7-16. https://doi.org/10.1080/14622200124218

Dethier V, Heeren A, Galanti L, Philippot P, Billieux J. 2014. Probing smoking craving with a multidimensional approach: validation of the 12-item French-language version of the 
495 Questionnaire on Smoking Urges. Neuropsychiatric disease and treatment 10:1459-1468.

496 https://dx.doi.org/10.2147\%2FNDT.S63090

497 Enkema MC, Bowen S. 2017. Mindfulness practice moderates the relationship between craving

498 and substance use in a clinical sample. Drug and Alcohol Dependence, 179, 1-7.

499 https://doi.org/10.1016/j.drugalcdep.2017.05.036

500 Faul F, Erdfelder E, Lang AG, Buchner A. 2007. G* Power 3: A flexible statistical power

501 analysis program for the social, behavioral, and biomedical sciences. Behavior research

502 methods, 39(2), 175-191. https://doi.org/10.3758/BF03193146

503 Fornell C, Larcker DF. 1981. Evaluating structural equation models with unobservable

504 variables and measurement error. Journal of marketing research, 18(1), 39-50.

505 https://doi.org/10.1177\%2F002224378101800104

506 Gao K, Shi X, Wang W. 2017. The life-course impact of smoking on hypertension, myocardial

507 infarction and respiratory diseases. Scientific reports 7(1):1-7. https://doi.org/10.1038/s41598-

$508 \quad \underline{017-04552-5}$

509 Guillin O, Krebs MO, Bourdel MC, Olie JP, Loo H, Poirier MF. 2000. Validation of the

510 French translation and factorial structure of the Tiffany and Drobes Smoking Urge

511 Questionnaire. L'Encephale 26(6):27-31.

512 Hair JF, Black WC, Babin BJ, Anderson RE. 1998. Multivariate Data Analysis: A Global

513 Perpective. Pearson Press.

514 Hair JF, Hult GTM, Ringle CM, Sarstedt M. 2021. A primer on partial least squares

515 structural equation modeling (PLS-SEM). Sage publications.

516 Hatcher L. 1996. Using SAS ${ }^{2}$ PROC CALIS for path analysis: An introduction. Structural

517 Equation Modelling: A Multidisciplinary Journal 3(2): 176-192.

518 https://doi.org/10.1080/10705519609540037

519 Heishman SJ, Singleton EG, Moolchan ET. 2003. Tobacco Craving Questionnaire: Reliability

520 and validity of a new multifactorial instrument. Nicotine \& tobacco research 5(5):645-654.

521 https://doi.org/10.1080/1462220031000158681

522 Henson RK, Roberts JK. 2006. Use of exploratory factor analysis in published research:

523 Common errors and some comment on improved practice. Educational and Psychological

524 measurement 66(3):393-416. https://doi.org/10.1177\%2F0013164405282485

525 Hu LT, Bentler PM. 1999. Cutoff criteria for fit indexes in covariance structure analysis:

526 Conventional criteria versus new alternatives. Structural equation modeling: a multidisciplinary

527 journal 6(1):1-55. https://doi.org/10.1080/10705519909540118

528 Jöreskog KG, Sörbom D. 1981. LISREL 5: analysis of linear structural relationships by

529 maximum likelihood and least squares methods; [user's guide]. University of Uppsala.

530 Joseph S, Grimshaw G, Amjad N, Stanton A. 2005. Self-motivation for smoking cessation

531 among teenagers: Preliminary development of a scale for assessment of controlled and

532 autonomous regulation. Personality and individual differences 39(5):895-902.

533 https://doi.org/10.1016/j.paid.2005.02.027 
534 Jung S, Takane Y. 2008. Regularized common factor analysis. New trends in psychometrics

535 Universal Academy Press.

536 Kazemitabar M, Moghadamzadeh A, Habibi M, Hakimzadeh R, Garcia D. 2020. School

537 health assessment tools: a systematic review of measurement in primary schools. PeerJ 8:e9459.

538 https://doi.org/10.7717/peerj.9459

539 Kenny DA, McCoach DB. 2003. Effect of the number of variables on measures of fit in

540 structural equation modeling. Structural equation modeling 10(3):333-51.

541 https://doi.org/10.1207/S15328007SEM1003 1

542 Kieffer KM. 1998. Orthogonal versus Oblique Factor Rotation: A Review of the Literature

543 regarding the Pros and Cons.

544 Killen JD, Fortmann SP. 1997. Craving is associated with smoking relapse: findings from three

545 prospective studies. Experimental and clinical psychopharmacology 5(2):137.

546 https://psycnet.apa.org/doi/10.1037/1064-1297.5.2.137

547 Kline RB. 2015. Principles and practice of structural equation modeling. Guilford publications.

548 Kozlowski LT, Pillitteri JL, Sweeney CT, Whitfield KE, Graham JW. 1996. Asking

549 questions about urges or cravings for cigarettes. Psychology of Addictive Behaviors 10(4):248.

550 https://psycnet.apa.org/doi/10.1037/0893-164X.10.4.248

551 Kyle RJ. 1999. Basic concepts of confirmatory factor analysis. InAnnual Meeting of the

552 Southwest Education Research Association.

553 Moosazadeh M, Ziaaddini H, Mirzazadeh A, Ashrafi-Asgarabad A, Haghdoost AA. 2013.

554 Meta-analysis of smoking prevalence in Iran. Addict Health 5(3-4):140-153.

555 Motschman CA, Germeroth LJ, Tiffany ST. 2018. Momentary changes in craving predict

556 smoking lapse behavior: a laboratory study. Psychopharmacology 235(7):2001-12.

557 https://doi.org/10.1007/s00213-018-4898-4

558 Müller V, Mucha RF, Ackermann K, Pauli P. 2001. The recording of craving in smokers with 559 a German version of the "Questionnaire on Smoking Urges" (QSU-G). Journal of Clinical

560 Psychology and Psychotherapy 30(3): 164-71. https://doi.org/10.1026/0084-5345.30.3.164

561 Muthén B, Muthén BO. 2009. Statistical analysis with latent variables. New York: Wiley.

562 NE MW, Cudeck R. 1993. Alternative ways of assessing model fit. Testing structural equation

563 models. 154:136.

564 Norris M, Lecavalier L. 2010. Evaluating the use of exploratory factor analysis in

565 developmental disability psychological research. Journal of autism and developmental disorders

566 40(1):8-20. https://doi.org/10.1007/s10803-009-0816-2

567 Nunnally JC. 1967. Psychometric theory. New York, NY: McGraw-Hill.

568 Onchonga D, Khatatbeh H, Thuranira M, Lennox K, Venkatesh MB. 2020. Assessing the

569 usability of a Willingness to Quit smoking questionnaire in a sample of active tobacco smokers:

570 A qualitative study. Journal of Addictive Diseases.

571 https://doi.org/10.1080/10550887.2020.1800891 
572 Pan B, Jin X, Jun L, Qiu S, Zheng Q, Pan M. 2019. The relationship between smoking and

573 stroke: A meta-analysis. Medicine 98(12): e14872.

574 https://doi.org/10.1097/MD.0000000000014872

575 Potvin S, Tikàsz A, Dinh-Williams LL, Bourque J, Mendrek A. 2015. Cigarette cravings, 576 impulsivity, and the brain. Frontiers in psychiatry 6:125.

577 https://doi.org/10.3389/fpsyt.2015.00125

578 Revelle W, Zinbarg RE. 2009. Coefficients alpha, beta, omega, and the glb: Comments on

579 Sijtsma. Psychometrika 74(1):145. https://doi.org/10.1007/s11336-008-9102-z

580 Serre F, Fatseas M, Denis C, Swendsen J, Auriacombe M. 2018. Predictors of craving and

581 substance use among patients with alcohol, tobacco, cannabis or opiate addictions:

582 Commonalities and specificities across substances. Addictive behaviors, 83, 123-129.

583 https://doi.org/10.1016/j.addbeh.2018.01.041

584 Scott JG, Matuschka L, Niemelä S, Miettunen J, Emmerson B, Mustonen A. 2018. Evidence

585 of a causal relationship between smoking tobacco and schizophrenia spectrum disorders.

586 Frontiers in psychiatry 9:607. https://doi.org/10.3389/fpsyt.2018.00607

587 Shahbazi Sighaldeh S, Baheiraei A, Ebadi A, Khaki I, Kelishadi R, Majdzadeh R. 2019.

588 Development and psychometric properties of the Hookah Smoking Initiation for Women

589 Questionnaire (HIWQ). Health promotion international 34(3):462-8.

590 https://doi.org/10.1093/heapro/dax085

591 Shiffman S, Waters AJ, Hickcox M. 2004. The nicotine dependence syndrome scale: a

592 multidimensional measure of nicotine dependence. Nicotine \& Tobacco Research 6(2):327-48.

593 Shiffman S, West RJ, Gilbert DG. 2004. Recommendation for the assessment of tobacco

594 craving and withdrawal in smoking cessation trials. Nicotine \& Tobacco Research 6(4):599-614.

595 https://doi.org/10.1080/14622200410001734067

596 Sterling KL, Mermelstein R, Turner L, Diviak K, Flay B, Shiffman S. 2009. Examining the

597 psychometric properties and predictive validity of a youth-specific version of the Nicotine

598 Dependence Syndrome Scale (NDSS) among teens with varying levels of smoking. Addictive

599 Behaviors 34(6-7):616-619. https://dx.doi.org/10.1016\%2Fj.addbeh.2009.03.016

600 Taber KS. 2018. The use of Cronbach's alpha when developing and reporting research

601 instruments in science education. Research in Science Education 48(6):1273-96.

602 https://doi.org/10.1007/s11165-016-9602-2

603 Teneggi V, Oprandi N, Milleri S, Squassante L, Niero M, Berto D, Bye A. 2001. Verifica

604 della validità esteriore e del contenuto della versione italiana di tre questionari su craving e

605 astinenza da fumo di sigarette [Assessment of face and content validity of the Italian version of

606 three questionnaires on cigarette smoke craving and withdrawal]. Giornale di Psicopatologia

607 7(4):378-86.

608 Tiffany ST, Drobes DJ. 1991. The development and initial validation of a questionnaire on 609 smoking urges. British Journal of addiction 86(11):1467-76. https://doi.org/10.1111/j.1360-

$610 \quad \underline{0443.1991 . t b 01732 . x}$ 
611 Toll BA, McKee SA, Krishnan-Sarin S, O'Malley SS. 2004. Revisiting the factor structure of 612 the questionnaire on smoking urges. Psychological assessment 16(4):391.

613 https://psycnet.apa.org/doi/10.1037/1040-3590.16.4.391

614 Tucker LR, Lewis C. 1973. A reliability coefficient for maximum likelihood factor analysis.

615 Psychometrika 38(1):1-10. https://doi.org/10.1007/BF02291170

616 Waltz CF, Bausell RB. 1981. Nursing research: Design, statistics, and computer analysis. $F A$

617 Davis Co.

618 Wang, Q.Q., Kaelber, D.C., Xu, R. et al. 2021. COVID-19 risk and outcomes in patients with 619 substance use disorders: analyses from electronic health records in the United States. Molecular 620 Psychiatry, 26, 30-39. https://doi.org/10.1038/s41380-020-00880-7

621 Waters AJ, Szeto EH, Wetter DW, Cinciripini PM, Robinson JD, Li Y. 2013. Cognition and 622 craving during smoking cessation: an ecological momentary assessment study. nicotine \& 623 tobacco research 16(Suppl_2):S111-S118. https://doi.org/10.1093/ntr/ntt108

624 Wong, K. M., \& Cloninger, C. R. 2010. A personcentered approach to clinical practice. Focus, 625 8(2), 199-215. https://doi.org/10.1176/foc.8.2.foc199.

626 World Health Organization. 2020. Leading cause of death, illness and impoverishment.

627 Retrieved from https://www.who.int/news-room/fact-sheets/detail/tobacco (accessed

628 10/23/2020).

629 World Health Organization. 2020. WHO Report on the Global Tobacco Epidemic, 2008. The 630 MPOWER Package. Geneva: WHO, 2008. World Health Organization,[http://www. who. $631 \mathrm{int} /$ tobacco/mpower/en/index. html]. Retrieved from https://www.who.int/news-room/fact632 sheets/detail/tobacco (accessed 09/07/2020).

633 Worthington RL, Whittaker TA. 2006. Scale development research: A content analysis and 634 recommendations for best practices. The counseling psychologist 34(6):806-38.

635 https://doi.org/10.1177\%2F0011000006288127

636 Yu X, Xiao D, Li B, Liu Y, Wang G, Chen J, Bai C, Pan J, Wan H, Li Q, Zhou X. 2010.

637 Evaluation of the Chinese versions of the Minnesota nicotine withdrawal scale and the 638 questionnaire on smoking urges-brief. Nicotine \& Tobacco Research 12(6):630-4.

639 https://doi.org/10.1093/ntr/ntq063

640 Yuan S, Larsson SC. 2019. A causal relationship between cigarette smoking and type 2 diabetes 641 mellitus: A Mendelian randomization study. Scientific reports 9(1):1-4.

642 https://doi.org/10.1038/s41598-019-56014-9 


\section{Table $\mathbf{1}$ (on next page)}

Factor loadings of the QSU 12-items using maximum likelihood exploratory factor analysis 


\section{Table 1:}

2 Factor loadings of the QSU 12-items using maximum likelihood exploratory factor analysis

\begin{tabular}{|c|c|c|}
\hline \multirow{2}{*}{ Items } & \multicolumn{2}{|c|}{ Factors } \\
\cline { 2 - 3 } & \multicolumn{2}{|c|}{} \\
\hline QSU1 & .95 & .38 \\
\hline QSU2 & .92 & .36 \\
\hline QSU4 & .94 & .42 \\
\hline QSU7 & .87 & .29 \\
\hline QSU9 & .93 & .39 \\
\hline QSU10 & .89 & .31 \\
\hline QSU12 & .94 & .36 \\
\hline QSU3 & .34 & .92 \\
\hline QSU5 & .36 & .85 \\
\hline QSU6 & .33 & .87 \\
\hline QSU8 & .35 & .93 \\
\hline QSU11 & .34 & .89 \\
\hline
\end{tabular}

3 


\section{Table 2 (on next page)}

Fit indices for the confirmatory factor analysis of the 1 and 2 factor models of the QSU 12-item 
2 Table 2:

3 Fit indices for the confirmatory factor analysis of the 1 and 2 factor models of the QSU 124 item

\begin{tabular}{|c|c|c|c|c|c|c|c|c|}
\hline Model & $\chi^{2}$ & $\mathrm{df}$ & $\chi^{2 / \mathrm{df}}$ & $\rho$ & $\begin{array}{c}\text { RMSEA } \\
(\mathrm{CI}=90 \%)\end{array}$ & CFI & TLI & SRMR \\
\hline 1-factor & 921.81 & 54 & 17.07 & 0.00 & 0.25 & 0.76 & 0.70 & 0.14 \\
\hline 2-factor (modified) & 221.88 & 53 & 4.18 & 0.00 & 0.09 & 0.95 & 0.94 & 0.04 \\
\hline 2-factor (original) & 562.17 & 53 & 10.60 & 0.00 & 0.19 & 0.86 & 0.82 & 0.12 \\
\hline
\end{tabular}

5 Note. RMSEA: Root Mean Square Error of Approximation; CFI: Comparative Fit Index; TLI:

6 Tucker-Lewis Index, SRMR: Standardized Root Mean Square Residual 
Table 3 (on next page)

CR, AVE, and AVE2 of the Factors of the Persian version of the QSU 12-item 
1

2 Table 3:

3 CR, AVE, and AVE ${ }^{2}$ of the Factors of the Persian version of the QSU 12-item

\begin{tabular}{|c|c|c|c|}
\hline Factors & CR & AVE & AVE $^{2}$ \\
\hline 1 & .95 & .79 & .62 \\
\hline 2 & .98 & .87 & .75 \\
\hline
\end{tabular}

4 Note. CR: composite reliability, AVE: average variance extracted. 


\section{Table 4 (on next page)}

Correlation matrix for the Persian version of the QSU 12-item (modified 2-factor solution model). 
2 Table 4:

3 Correlation matrix for the Persian version of the QSU 12-item (modified 2-factor solution 4 model).

\begin{tabular}{|l|l|l|l|l|l|l|l|l|l|l|l|l|}
\hline & \multicolumn{3}{|l|}{ Factor 1} & \multicolumn{3}{l|}{ Factor 2} \\
\hline Item & 3 & 5 & 6 & 8 & 11 & 1 & 2 & 4 & 7 & 9 & 10 & 12 \\
\hline 3 & - & & & & & & & & & & & \\
\hline 5 & .71 & - & & & & & & & & & & \\
\hline 6 & .75 & .76 & - & & & & & & & & & \\
\hline 8 & .80 & .71 & .73 & - & & & & & & & & \\
\hline 11 & .78 & .72 & .83 & .78 & - & & & & & & & \\
\hline 1 & & & & & & - & & & & & & \\
\hline 2 & & & & & & .89 & - & & & & & \\
\hline 4 & & & & & & .89 & .85 & - & & & & \\
\hline 7 & & & & & & .81 & .82 & .84 & - & & & \\
\hline 9 & & & & & & .89 & .86 & .89 & .80 & - & & \\
\hline 10 & & & & & & .83 & .82 & .81 & .83 & .82 & - & \\
\hline 12 & & & & & & .88 & .87 & .88 & .82 & .87 & .84 & - \\
\hline
\end{tabular}

5 


\section{Table 5 (on next page)}

Mann-Whitney and Kruskal-Wallis tests for comparing subgroups in smoking urges and craving as measure by the QSU 12-item (modified 2-factor solution model). 
2 Table 5:

3 Mann-Whitney and Kruskal-Wallis tests for comparing subgroups in smoking urges and 4 craving as measure by the QSU 12-item (modified 2-factor solution model).

\begin{tabular}{|c|c|c|c|c|c|c|}
\hline \multirow[t]{12}{*}{ QSU } & \multirow{2}{*}{\multicolumn{2}{|c|}{ Groups }} & \multirow[t]{2}{*}{$\mathrm{N}$} & \multirow{2}{*}{$\begin{array}{l}\text { Mean } \\
\text { Rank }\end{array}$} & \multicolumn{2}{|c|}{ Mann-Whitney Test } \\
\hline & & & & & $\mathrm{U}$ & $\begin{array}{c}p- \\
\text { value }\end{array}$ \\
\hline & \multirow[t]{2}{*}{ Gender } & Female & 172 & 194.35 & \multirow[t]{2}{*}{18550.00} & \multirow[t]{2}{*}{0.73} \\
\hline & & Male & 220 & 198.18 & & \\
\hline & \multirow[t]{2}{*}{ Marriage status } & Single & 353 & 197.08 & \multirow[t]{2}{*}{6679.00} & \multirow[t]{2}{*}{0.76} \\
\hline & & Married & 39 & 191.26 & & \\
\hline & \multirow{2}{*}{$\begin{array}{l}\text { Employment } \\
\text { status }\end{array}$} & Employed & 118 & 191.17 & \multirow[t]{2}{*}{15537.50} & \multirow[t]{2}{*}{0.54} \\
\hline & & Unemployed & 274 & 198.79 & & \\
\hline & \multirow{4}{*}{$\begin{array}{c}\text { Educational } \\
\text { level }\end{array}$} & & $\mathrm{N}$ & $\begin{array}{l}\text { Mean } \\
\text { Rank }\end{array}$ & $\begin{array}{c}\text { Kruskal-Wallis (Chi- } \\
\text { Square) }\end{array}$ & $\begin{array}{c}p- \\
\text { value }\end{array}$ \\
\hline & & Associate & 13 & 212.23 & \multirow{3}{*}{.51} & \multirow{3}{*}{0.77} \\
\hline & & Bachelor & 246 & 198.12 & & \\
\hline & & Master & 133 & 191.97 & & \\
\hline \multirow{10}{*}{$\begin{array}{c}\text { Factor } \\
1\end{array}$} & \multirow[t]{2}{*}{ Gender } & Female & 172 & 199.73 & \multirow[t]{2}{*}{18364.00} & \multirow[t]{2}{*}{0.61} \\
\hline & & Male & 220 & 193.97 & & \\
\hline & \multirow[t]{2}{*}{ Marriage status } & Single & 353 & 197.66 & \multirow[t]{2}{*}{6473.00} & \multirow[t]{2}{*}{0.54} \\
\hline & & Married & 39 & 185.97 & & \\
\hline & \multirow{2}{*}{$\begin{array}{l}\text { Employment } \\
\text { status }\end{array}$} & Employed & 118 & 203.63 & \multirow[t]{2}{*}{15324.50} & \multirow[t]{2}{*}{0.41} \\
\hline & & Unemployed & 274 & 193.43 & & \\
\hline & \multirow{4}{*}{$\begin{array}{c}\text { Educational } \\
\text { level }\end{array}$} & & $\mathrm{N}$ & $\begin{array}{l}\text { Mean } \\
\text { Rank }\end{array}$ & $\begin{array}{c}\text { Kruskal-Wallis (Chi- } \\
\text { Square) }\end{array}$ & $\begin{array}{c}p- \\
\text { value }\end{array}$ \\
\hline & & Associate & 13 & 193.77 & \multirow{3}{*}{.05} & \multirow{3}{*}{0.97} \\
\hline & & Bachelor & 246 & 197.47 & & \\
\hline & & Master & 133 & 194.97 & & \\
\hline
\end{tabular}




\begin{tabular}{|c|c|c|c|c|c|c|}
\hline \multirow{10}{*}{$\begin{array}{c}\text { Factor } \\
2\end{array}$} & \multirow[t]{2}{*}{ Gender } & Female & 172 & 193.71 & \multirow[t]{2}{*}{18440.000} & \multirow[t]{2}{*}{0.666} \\
\hline & & Male & 220 & 198.68 & & \\
\hline & \multirow[t]{2}{*}{ Marriage status } & Single & 353 & 197.52 & \multirow[t]{2}{*}{6522.500} & \multirow[t]{2}{*}{0.590} \\
\hline & & Married & 39 & 187.24 & & \\
\hline & \multirow{2}{*}{$\begin{array}{l}\text { Employment } \\
\text { status }\end{array}$} & Employed & 118 & 189.13 & \multirow[t]{2}{*}{15296.500} & \multirow[t]{2}{*}{0.397} \\
\hline & & Unemployed & 274 & 199.67 & & \\
\hline & \multirow{4}{*}{$\begin{array}{l}\text { Educational } \\
\text { level }\end{array}$} & & $\mathrm{N}$ & $\begin{array}{l}\text { Mean } \\
\text { Rank }\end{array}$ & $\begin{array}{c}\text { Kruskal-Wallis (Chi- } \\
\text { Square) }\end{array}$ & $\begin{array}{c}p- \\
\text { value }\end{array}$ \\
\hline & & Associate & 13 & 229.92 & \multirow[t]{3}{*}{1.758} & \multirow[t]{3}{*}{0.415} \\
\hline & & Bachelor & 246 & 198.62 & & \\
\hline & & Master & 133 & 189.31 & & \\
\hline
\end{tabular}

5 


\section{Figure 1}

\section{Path diagram for the Persian version of the QSU 12-item}

Note. The values out of parentheses indicate factor loadings, the values inside the parentheses indicate standard error of estimates, and the numbers in rectangles indicate items' number. 


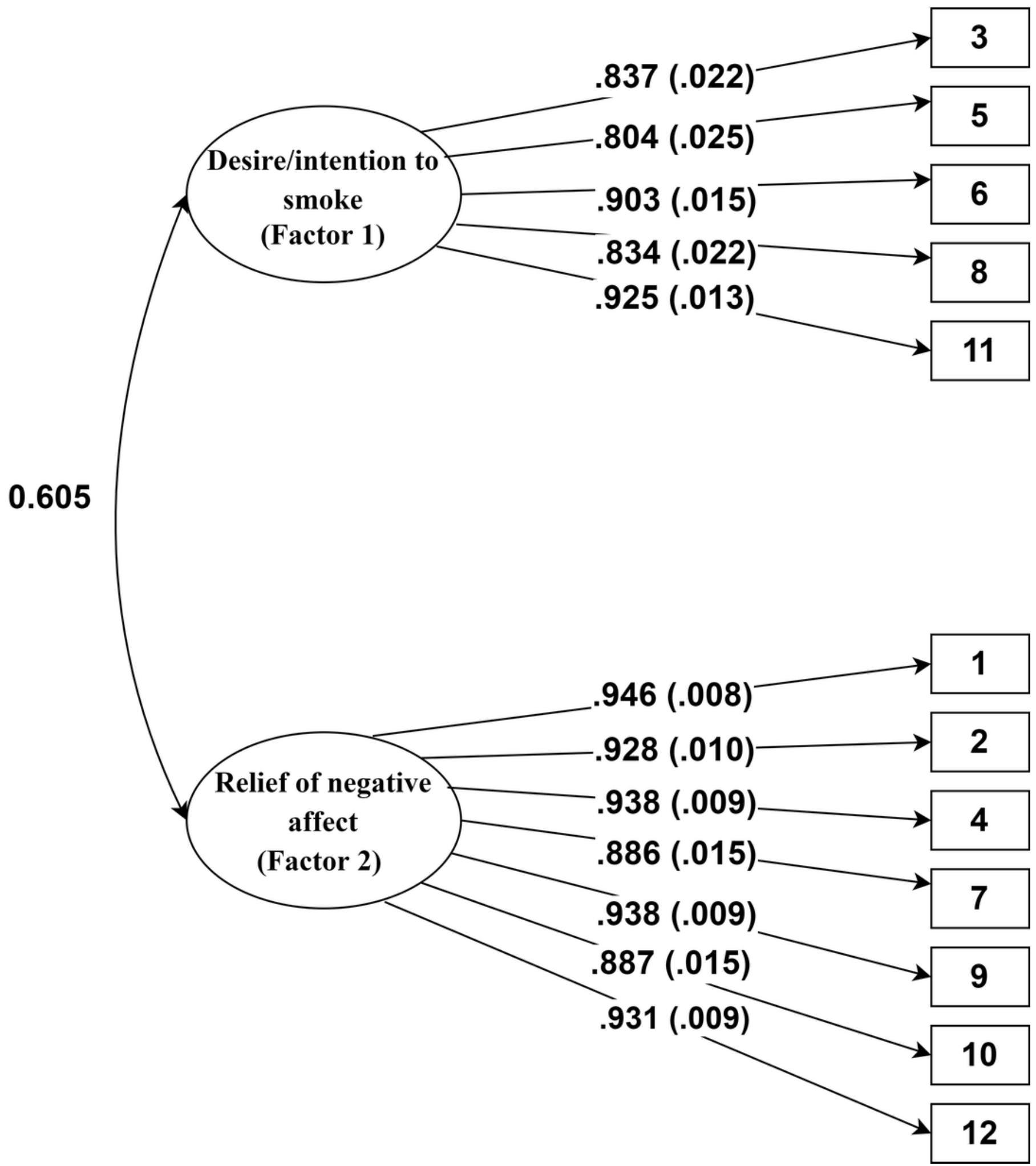




\section{Table 6(on next page)}

The expert panel judgement on content validity of the Persian version of the QSU 12item 
2 The expert panel judgement on content validity of the Persian version of the QSU 12-item

\begin{tabular}{|c|c|c|c|}
\hline Criteria & Items & Range & $\mathrm{CVI}$ \\
\hline \multirow[t]{12}{*}{ Relevance } & 1 & $2.0-4.0$ & 0.8 \\
\hline & 2 & $3.0-4.0$ & 1.0 \\
\hline & 3 & $3.0-4.0$ & 1.0 \\
\hline & 4 & $2.0-4.0$ & 0.9 \\
\hline & 5 & $3.0-4.0$ & 1.0 \\
\hline & 6 & $3.0-4.0$ & 1.0 \\
\hline & 7 & $3.0-4.0$ & 1.0 \\
\hline & 8 & $3.0-4.0$ & 1.0 \\
\hline & 9 & $1.0-4.0$ & 0.8 \\
\hline & 10 & $2.0-4.0$ & 0.9 \\
\hline & 11 & $3.0-4.0$ & 1.0 \\
\hline & 12 & $2.0-4.0$ & 0.8 \\
\hline \multirow[t]{12}{*}{ Comprehensiveness } & 1 & $3.0-4.0$ & 1.0 \\
\hline & 2 & $3.0-4.0$ & 1.0 \\
\hline & 3 & $2.0-4.0$ & 0.9 \\
\hline & 4 & $3.0-4.0$ & 1.0 \\
\hline & 5 & $3.0-4.0$ & 1.0 \\
\hline & 6 & $3.0-4.0$ & 1.0 \\
\hline & 7 & $2.0-4.0$ & 0.9 \\
\hline & 8 & $2.0-4.0$ & 0.9 \\
\hline & 9 & $3.0-4.0$ & 1.0 \\
\hline & 10 & $1.0-4.0$ & 0.8 \\
\hline & 11 & $2.0-4.0$ & 0.9 \\
\hline & 12 & $1.0-4.0$ & 0.8 \\
\hline \multirow[t]{12}{*}{ Clarity } & 1 & $3.0-4.0$ & 1.0 \\
\hline & 2 & $3.0-4.0$ & 1.0 \\
\hline & 3 & $2.0-4.0$ & 0.9 \\
\hline & 4 & $3.0-4.0$ & 1.0 \\
\hline & 5 & $2.0-4.0$ & 0.9 \\
\hline & 6 & $3.0-4.0$ & 1.0 \\
\hline & 7 & $2.0-4.0$ & 0.8 \\
\hline & 8 & $1.0-4.0$ & 0.8 \\
\hline & 9 & $3.0-4.0$ & 1.0 \\
\hline & 10 & $2.0-4.0$ & 0.9 \\
\hline & 11 & $3.0-4.0$ & 1.0 \\
\hline & 12 & $1.0-4.0$ & 0.8 \\
\hline
\end{tabular}

3 Note: A Likert four-point scale was used (1=bad, 2=rather bad, revision needed, 3=good but

4 minor revision is needed, and $4=$ very good); $\mathrm{CVI}=$ Content Validity Index 
Table 7 (on next page)

Persian version of the Questionnaire on Smoking Urges 12-item 
Appendix 2

Persian version of the Questionnaire on Smoking Urges 12-item

\begin{tabular}{|c|c|c|c|c|c|}
\hline Factor & Items & F. L. & S. E. & $t$-value & $\begin{array}{l}p \text { - } \\
\text { value }\end{array}$ \\
\hline F2 & $\begin{array}{l}\text { 1. Nothing would be better than smoking a } \\
\text { cigarette right now. }\end{array}$ & 0.946 & 0.008 & 122.016 & 0.000 \\
\hline F2 & 2. Smoking would make me less depressed. & 0.928 & 0.010 & 94.713 & 0.000 \\
\hline F1 & 3. Smoking a cigarette would not be pleasant. ${ }^{R}$ & 0.837 & 0.022 & 38.519 & 0.000 \\
\hline $\mathrm{F} 2$ & 4. All I want right now is a cigarette. & 0.938 & 0.009 & 107.739 & 0.000 \\
\hline F1 & $\begin{array}{l}\text { 5. Even if it were possible, I probably wouldn't } \\
\text { smoke now. }{ }^{\text {R }}\end{array}$ & 0.804 & 0.025 & 32.054 & 0.000 \\
\hline F1 & 6. I have no desire for a cigarette right now. ${ }^{R}$ & 0.903 & 0.015 & 61.068 & 0.000 \\
\hline F2 & $\begin{array}{l}\text { 7. Smoking now would make things seem just } \\
\text { perfect. }\end{array}$ & 0.886 & 0.015 & 60.440 & 0.000 \\
\hline F1 & 8. A cigarette would not taste good right now. ${ }^{R}$ & 0.834 & 0.022 & 37.657 & 0.000 \\
\hline F2 & 9. I have an urge for a cigarette. & 0.938 & 0.008 & 114.791 & 0.000 \\
\hline F2 & $\begin{array}{l}\text { 10. I could control things better right now if I } \\
\text { could smoke. }\end{array}$ & 0.888 & 0.009 & 108.509 & 0.000 \\
\hline F1 & 11. I am going to smoke as soon as possible. & 0.925 & 0.013 & 73.548 & 0.000 \\
\hline F2 & $\begin{array}{l}\text { 12. I would do almost anything for a cigarette } \\
\text { now. }\end{array}$ & 0.931 & 0.009 & 98.755 & 0.000 \\
\hline
\end{tabular}

4 Note. $\mathrm{R}=$ Reversed items; F. L.= Factor Loading; S. E.= Standard Error. 
Table 8(on next page)

Persian version of the Questionnaire on Smoking Urges 12-item in Persian (Farsi) 
Appendix 3

2

"يرسشنامه سنجش ميل به سيخار كثيدن

\begin{tabular}{|c|c|c|c|c|c|c|c|c|}
\hline كو امقا & تقريبا & مو افق & 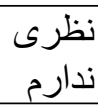 & 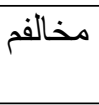 & تقريبا & 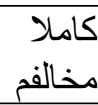 & 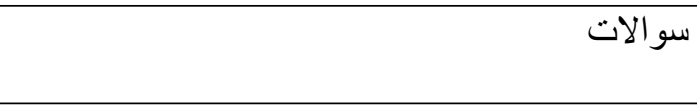 & \\
\hline & & & & & & & الان هيج جيز بهتر از يك نخ سيحار نيست. & 1 \\
\hline & & & & & & & سيخار باعث مى شود كمتر احساس افسردگى كنم. & 2 \\
\hline & & & & & & & سيخار كثيدن اصلا لذت بخش نيست. & 3 \\
\hline & & & & & & & تمام آنجه همين الان مىخو اهم فقط يك نخ سيكار & 4 \\
\hline & & & & & & & حتى اكر الان امكانش فر اهم بود، سيكار نمىكثيدم. & 5 \\
\hline & & & & & & & الان تمايلى به كثيدن سيگار ندارم. & 6 \\
\hline & & & & & & & نظر هاكين الان يكى نيخ سيخار مىكثيدم، همه جيز به & 7 \\
\hline & & & & & & & الان سيكار كثيدن حس خوبى به من نمىدهد. & 8 \\
\hline & & & & & & & احساس مى كنم همين الان بايد يك نخ سيحار بكشم. & 9 \\
\hline & & & & & & & 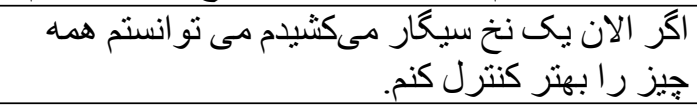 & 10 \\
\hline & & & & & & & مى خو اهم هر جه زودتر يك نخ سيگار بكشم. & 11 \\
\hline & & & & & & & هر كارى بيكه همين الان يكـ نخ سيكار بكشم حاضرم & 12 \\
\hline
\end{tabular}

3

Questionnaire on Smoking Urges 12-item (Kozlowski et al., اين يرسشنامه نسخه ترجمه و هنجاريابى شده *

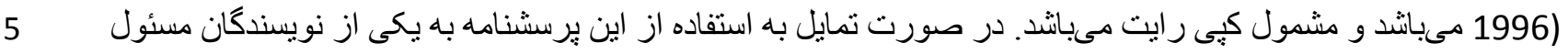
6

مقاله جهت دريافت مجوز ايميل بدهيد. 